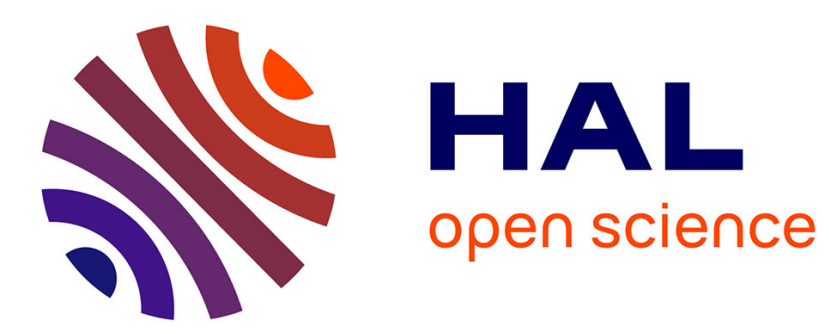

\title{
Pupillary response to cognitive workload during saccadic tasks in Parkinson's disease
}

Maud Ranchet, Jason Orlosky, John Morgan, Siraj Qadir, Abiodun Emmanuel Akinwuntan, Hannes Devos

\section{- To cite this version:}

Maud Ranchet, Jason Orlosky, John Morgan, Siraj Qadir, Abiodun Emmanuel Akinwuntan, et al.. Pupillary response to cognitive workload during saccadic tasks in Parkinson's disease. Behavioural Brain Research, 2017, 327, pp. 162-166. 10.1016/j.bbr.2017.03.043 . hal-01510129v2

\section{HAL Id: hal-01510129 \\ https://hal.science/hal-01510129v2}

Submitted on 19 Apr 2017

HAL is a multi-disciplinary open access archive for the deposit and dissemination of scientific research documents, whether they are published or not. The documents may come from teaching and research institutions in France or abroad, or from public or private research centers.
L'archive ouverte pluridisciplinaire HAL, est destinée au dépôt et à la diffusion de documents scientifiques de niveau recherche, publiés ou non, émanant des établissements d'enseignement et de recherche français ou étrangers, des laboratoires publics ou privés. 
RANCHET, Maud, ORLOSKY, Jason, MORGAN, John, QADIR, Siraj, AKINWUNTAN, Abiodun Emmanuel, DEVOS, Hannes, 2017, Pupillary response to cognitive workload during saccadic tasks in Parkinson's disease, Behavioural Brain Research, 327, Elsevier, pp. 162-166, DOI: 10.1016/j.bbr.2017.03.043

\section{This is a pre-print version of the manuscript}

\section{Pupillary Response to Cognitive Workload during Saccadic Tasks in Parkinson's}

\section{Disease}

Order of authors: M. Ranchet, $\mathrm{PhD}^{1,2}$, J. Orlosky, $\mathrm{PhD}^{3}$, J. Morgan, $\mathrm{MD}, \mathrm{PhD}^{4}$, S. Qadir, $\mathrm{BS}^{5}$, A. E. Akinwuntan PhD, MPH, MBA ${ }^{1,6}$, H. Devos, $\mathrm{PhD}^{1,7}$

${ }^{1}$ Department of Physical Therapy, College of Allied Health Sciences, Augusta University, Augusta, GA, USA

${ }^{2}$ Université de Lyon, F-69000 Lyon, France-IFSTTAR, TS2, LESCOT, F-69500 Bron

${ }^{3}$ Cybermedia Center, Toyonaka Educational Research Center 5F, Osaka University, 1-32

Machikaneyama, Toyonaka, Osaka 560-0043, Japan

${ }^{4}$ Movement and Cognitive Disorders Center, Department of Neurology, Augusta University, GA, USA

${ }^{5}$ Medical College of Georgia, Augusta University, GA, USA

${ }^{6}$ Dean's office, School of Health Professions, The University of Kansas Medical Center, Kansas City, KS, USA

${ }^{7}$ Department of Physical Therapy and Rehabilitation Science, School of Health Professions, The University of Kansas Medical Center, Kansas City, KS, USA

Corresponding author:

Maud Ranchet, IFSTTAR, TS2-LESCOT

Cité des mobilités

25, Avenue François Mitterrand

69675 Bron Cedex, France

Phone: +33 (0)4 72142599

Email: maud.ranchet@ifsttar.fr

Word count: 2977 words (inclusive of abstract references and figure legends) 
Running title: Cognitive workload in Parkinson's disease

Financial Disclosure/ Conflict of Interest: the authors have no financial disclosures and report no conflict of interest

Funding sources for the study: funded in part by the American Parkinson's Disease Association 
Abstract

The relationship between cognitive workload and cognitive impairments in Parkinson's disease (PD) is currently not well known. This study compared cognitive workload during saccadic tasks between patients with PD and controls. Sixteen controls, 11 patients with no obvious cognitive impairment (PD-NCI) (MOCA score $\geq 26$ ), and 10 PD patients with cognitive impairment (PD-CI) (MOCA score < 26) performed prosaccade and antisaccade tasks. Cognitive workload, extracted via pupil recording, and other eye metrics were compared between the three groups. PD-NCI patients exhibited greater cognitive workload than controls in the prosaccade task. PD-CI patients also showed more cognitive workload in the prosaccade task than PD-NCI patients and controls. No other differences in eye metrics were found between the three groups. Cognitive workload could be used to differentiate between different cognitive states in PD. The causal relationship between increased cognitive workload and cognitive decline in PD-NCI should be the focus of future studies.

Keywords - up to 6: Parkinson's disease, cognitive workload, prosaccade task, antisaccade task, executive function 


\section{Introduction}

With increasing life expectancy and aging of the population, the number of patients with Parkinson's disease (PD) is also projected to increase, reaching 9.2 million by 2030 worldwide [1]. In addition to motor symptoms, patients may exhibit cognitive symptoms that affect activities of daily living [2,3]. About $25 \%$ of patients with PD suffer from such cognitive impairments at the time of diagnosis [4]. Neuropsychological tests are used in the clinic to detect cognitive impairments. However, they may be inadequate to recognize subtle cognitive changes. Hence, more sensitive neurophysiological measures such as pupillometry are currently being utilized to identify early cognitive impairment in PD [5]. Task-evoked pupillary response (TEPR) has been successfully used to accurately estimate cognitive workload that is representative of cognitive impairments in adults [6-8]. TEPR is caused by a decrease in parasympathetic activity in the peripheral nervous system because of increased cognitive workload [9]. As acetylcholine is the main neurotransmitter that mediates TEPR and other pupillary reflexes, cognitive impairment, which mainly reflects a central cholinergic deficit, may be preceded by abnormal TEPR [10]. Previous studies have used TEPR to evaluate arithmetic capabilities and executive functions in PD [5,11]. Yet, to our knowledge, no study has examined whether TEPR discriminates between different cognitive states of PD. In this study, we used prosaccade and antisaccade tasks to examine cognition in PD [12]. The prosaccade task involves information processing speed whereas the antisaccade assesses executive functions $[5,13,14]$. Our main objective was to compare cognitive workload, extracted from TEPR of both eyes, between controls, patients with no obvious cognitive impairments (PD-NCI), and patients with cognitive impairments (PD-CI) in prosaccade and antisaccade tasks. A secondary aim was to correlate cognitive workload with performance in a test assessing global cognitive function and age.

\section{Methods}




\subsection{Participants}

Sixteen controls and 21 patients from the Movement Disorders Clinic at Augusta University were included (Table 1). PD patients with dementia (Montreal Cognitive Assessment (MOCA) scores $\leq 15$ ), other parkinsonian syndromes, severe dyskinesia, deep brain stimulation, or unpredictable motor fluctuations were excluded. L-Dopa equivalent dosages [15] as well as motor scores on Unified Parkinson's Disease Rating Scale (UPDRS) were recorded. All but one patient were medicated and were tested in the "on" state, due to task difficulty $[14,16]$. MOCA score > 26 was used to discern PD-NCI patients from PD-CI patients [17]. Eleven patients had PD-NCI and 10 had PD-CI. Of those, 4 scored between 20 and 25 (mild cognitive impairment) and 6 scored between 16 and 20 (moderate cognitive impairment) on the MOCA [17]. The study was approved by an institutional review board. Informed written consent was obtained from all subjects. 


\subsection{Saccadic tasks}

The prosaccade and antisaccade tasks consisted of 132 trials each, with a duration of nine minutes (Figure 1A). Each task contained both gap and overlap trials to maximize task sensitivity [18]. The color and size of the target as well as the color of the background were carefully considered after review of the literature. For the prosaccade task, participants were instructed to shift gaze from the central fixation point to a peripheral target. In the gap condition, the fixation point disappeared after $1000 \mathrm{~ms}$ and, following a gap interval of 200 ms, the eccentric target appeared. In the overlap condition, the fixation point remained visible when the eccentric target appeared and throughout the remainder of the trial. Eccentricity of the target varied from $5^{\circ}$ to $50^{\circ}$ of visual angle from the central target. There were 22 different target locations. The target appeared randomly either to the left or right side and remained visible for $3000 \mathrm{~ms}$, after which the next trial started. The participant had to press a button as soon as the target was noticed. Response time to the button press was recorded. Fixation condition (gap/overlap), eccentricity (10 levels), and target location (left/right), were randomly interleaved throughout each block of the trials. Each block included 40 experimental conditions that were repeated three times. Twelve additional trials containing a target located vertically at $5^{\circ}$ of visual angle from the central target were added in order to vary the location of targets. The antisaccade task used the same visual presentations as in the prosaccade task. The participants were instructed to look away from the eccentric target to its mirror location and press a response button.

\subsection{Saccadic Eye Movement Recordings}

TEPR and eye movements were recorded by two synchronized, remote eye trackers (FOVIO, SeeingMachines Inc, Canberra, Australia) at $60 \mathrm{~Hz}$. TEPR detects small but reliable increases in pupil size while adjusting for individual differences in pupil size, lighting, and 
accommodation [8]. The TEPR values were transformed to a continuous scale of cognitive workload ranging between 0 and 1, and were computed for left and right eyes [8]. Prosaccade latencies and antisaccade errors were collected given their strong association with cognition [12]. Prosaccade latencies for correct trials were measured as the duration from the target appearance to the onset of the first eye movement. Only latencies for correct trials between 90 and $1000 \mathrm{~ms}$ were analyzed [16]. Antisaccade errors were defined as the first saccade after stimulus appearance that is executed in the wrong direction. To make sure we recorded antisaccade errors, a detection algorithm was applied when the eye position exceeded half the target position in the opposite direction.

\section{Statistical analysis}

Between-group differences were examined using non-parametric or parametric tests based on the normality testing. Post-hoc analyses with Bonferroni correction for multiple comparisons were employed to investigate between-group differences. Within-group differences were examined using paired t-tests or Wilcoxon signed-rank tests. Generalized linear models were used to determine the main effects of age and group on the cognitive workload for each eye. Spearman rho correlations were performed between cognitive workload for each eye and demographic, clinical, behavioral and eye-related variables.

\section{Results}

\subsection{Cognitive workload}

In the prosaccade task, significant between-group differences were found in cognitive workload for the left eye and the right eye. PD-CI patients had greater cognitive workload for the left eye than controls (PD-CI patients, median (Q1 - Q3): 0.36 (0.36-0.40); Controls: $0.30(0.27-0.35), \mathrm{p}=0.02)$. They also had greater cognitive workload for the right eye than PD-NCI patients and controls (PD-CI patients: $0.41(0.41-0.41)$; PD-NCI: 0.37 (0.35 - 
0.38); Controls: $0.30(0.28-0.31), \mathrm{p}<0.001)$ (Figure 1B). PD-NCI patients had greater cognitive workload than controls, but only for the right eye. No effect of age $(p>0.05)$ on cognitive workload for either eye was found. Yet, since age differed significantly between the

three groups (Table 1), we adjusted for age in the generalized linear model. The main effect of group on cognitive workload on the right eye remained significant $(\mathrm{p}<0.001)$.

In the antisaccade task, significant between-group differences were found only in the right eye. PD-CI patients had greater cognitive workload for the right eye than controls. There was no effect of age $(p=0.96)$ on cognitive workload in the right eye. There were no main effects of group on cognitive workload for both eyes, after correction for age differences $(p>0.05)$.

Within-group changes were only found in the PD-NCI group, with significantly lower cognitive workload in the antisaccade task compared to the prosaccade task, both in the left eye $(\mathrm{p}=0.049)$ and right eye $(\mathrm{p}=0.008)$.

\subsection{Prosaccade latency and antisaccade error rates}

No between-group differences in prosaccade latency and antisaccade error rates were found.

\subsection{Behavioral performance}

Significant differences in response times were found between the antisaccade task and the prosaccade task for the controls $(\mathrm{p}=0.046)$, PD-NCI patients $(\mathrm{p}=0.005)$, and PD-CI patients $(\mathrm{p}=0.001)$. No significant between-group differences in response times were found (Figure $1 \mathrm{C})$.

\subsection{Correlation between cognitive workload and other variables in all participants}

In the prosaccade task, cognitive workload for the right eye was correlated with MOCA score $($ rho $=-0.39, \mathrm{p}=0.02)$ and age $($ rho $=0.55, \mathrm{p}<0.001)$ whereas cognitive workload for the left 
eye was only correlated with age (rho $=0.39, \mathrm{p}=0.02)$. In the antisaccade task, cognitive workload for the left eye was correlated with error rate (rho $=0.40, \mathrm{p}=0.03$ ) and that for the right eye was correlated with age (rho $=0.41, \mathrm{p}=0.01)$.

\section{Discussion}

Cognitive workload discriminated between different states of cognitive severity. These findings may have implications for early detection and monitoring progression of subtle cognitive impairments in PD. Our results corroborate previous findings that showed the potential of pupil-based measures to examine executive deficits using an interleaved pro- and antisaccade paradigm in early PD [5]. However, this previous study included patients with MOCA score > 26. To our knowledge, this paper is the first evidence that cognitive workload, extracted from TEPR, discriminated between different cognitive states of PD. Our results show that cognitive workload in the right eye could be useful in the assessment of cognitive status in PD. We found associations between cognitive workload and cognitive status and significant group effects on cognitive workload, even after adjusting for age. Interestingly, TEPR from the right eye differentiated better between groups than from the left eye, which is consistent with previous results in PD using arithmetic tasks $[8,11]$. Hemispheric differences as reflected in left/right eye pupil measures, could contribute to performance on saccadic tasks in different ways $[19,20]$. It is possible that cognitive workload in the right eye may have been caused by greater activation of the left hemisphere, which is more involved in planning of next saccades than the right hemisphere and correlated with prosaccade gain $[19,20]$. Future studies will investigate TEPR in each of the eye in various cognitive tasks to determine the sensitivity of each eye to capture specific cognitive functions. We showed that the prosaccade task reflects more subtle cognitive changes between groups than the antisaccade task. The antisaccade task might be too difficult in PD groups, particularly for PD-CI patients. Reduction in cognitive workload between the antisaccade task and the prosaccade task in PD- 
NCI patients supports the idea that PD-NCI patients had limited resources to cope with increasing task demand and subsequently showed cognitive overload [9]. However, we did not find significant reduction in cognitive workload between both tasks in PD-CI patients, which could be explained by insufficient cognitive resources as severity progresses [21]. Although we found subtle cognitive between-group changes, we did not find between-group differences in prosaccade latency, which is consistent with previous studies including gap and overlap conditions in prosaccade tasks [22]. Surprisingly, we did not show significant between-group differences in antisaccade error rates. The use of medication [13,23,24], the large heterogeneity in the PD-CI group, as well as task design $[5,13,23]$ could explain this result. Cognitive workload could be useful to identify subtle cognitive changes between PDNCI patients and controls and to assess cognitive status in PD. Particularly, TEPR from the right eye seems to reflect subtle cognitive changes between groups in the prosaccade task. Future studies should also explore cognitive workload over time, using within-task variation of pupil changes in patients with PD [25].

\section{Funding}

This study was supported by a grant from the American Parkinson's Disease Association.

\section{Acknowledgements}

We thank the American Parkinson's Disease Association for funding this research.

Financial Disclosures

The authors reported no financial disclosures 
Table 1. Demographic and clinical characteristics, and scores in saccadic tasks in controls, patients with no obvious cognitive impairment (PD-NCI), patients with cognitive impairment (PD-CI)

\begin{tabular}{|c|c|c|c|c|}
\hline Variable & $\begin{array}{l}\text { Controls } \\
\mathrm{N}=16\end{array}$ & $\begin{array}{l}\text { PD-NCI } \\
\mathrm{N}=11\end{array}$ & $\begin{array}{l}\text { PD-CI } \\
\mathrm{N}=10\end{array}$ & $\mathrm{P}$ value \\
\hline Age, years & $61(54-69)$ & $69(61-72)$ & $71(69-76)$ & $\mathrm{KW}, 0.02^{\mathrm{a}}$ \\
\hline Sex (male), $\%$ & 50 & 64 & 90 & Fisher, 0.13 \\
\hline $\begin{array}{l}\text { Education, } \\
\text { years }\end{array}$ & $15(13-20)$ & $17(16-18)$ & $16.5(15.50-18)$ & $\mathrm{KW}, 0.62$ \\
\hline $\begin{array}{l}\text { MOCA score } \\
(0-30)\end{array}$ & $29(27.50-30)$ & $27(27-29)$ & $20(18-23)$ & $\mathrm{KW},<0.001^{\mathrm{b}}$ \\
\hline $\begin{array}{l}\text { Disease } \\
\text { duration, years }\end{array}$ & NA & $5(2-6)$ & $5.50(3-8)$ & $\mathrm{W}, 0.68$ \\
\hline LED, mg/day & NA & $300(0-855)$ & $463(300-1000)$ & $\mathrm{W}, 0.37$ \\
\hline $\begin{array}{l}\text { Hoehn and } \\
\text { Yahr stage } \\
\text { (on) }\end{array}$ & NA & $2(2-3)$ & $2(2-3)$ & $\mathrm{W}, 0.63$ \\
\hline $\begin{array}{l}\text { UPDRS motor } \\
\text { (on) }\end{array}$ & NA & $20(14-34)$ & $37.5(31-46)$ & $\mathrm{W}, 0.02$ \\
\hline $\begin{array}{l}\text { Prosaccade } \\
\text { latency }(\mathrm{ms})^{*}\end{array}$ & $\begin{array}{l}488.83(438.61- \\
43.69)\end{array}$ & $505.22(442.62-567.28)$ & $470.30(357.36-508.28)$ & ANOVA, 0.41 \\
\hline $\begin{array}{l}\text { Antisaccade } \\
\text { error rates (\%) }\end{array}$ & $20.53(14.93-31.82)$ & $13.82(7.26-31.98)$ & $29.52(19.16-30.64)$ & $\mathrm{KW}, 0.53$ \\
\hline
\end{tabular}

ANOVA, Analysis of variance; KW, Kruskall-Wallis test; LED, L-Dopa Equivalent Dosage; NA, not applicable; W, Wilcoxon test

Values are expressed as mean $\pm \mathrm{SD}$, frequencies $(\%=$ percentage $)$, or medians $(\mathrm{Q} 1-\mathrm{Q} 3)$

${ }^{\mathrm{a}} \mathrm{C}<\mathrm{PD}-\mathrm{CI}$ greater score in patients with CI compared to controls (post-hoc test with Bonferroni correction $\mathrm{p}<0.017$ )

${ }^{\mathrm{b}} \mathrm{C}>\mathrm{PD}-\mathrm{CI}$ poorer performances in patients with $\mathrm{CI}$ compared to controls (post-hoc test with Bonferroni correction $\mathrm{p}<0.017$ )

*Due to technical problems, 3 participants (2 patients and 1 control) had missing values for eye data) 

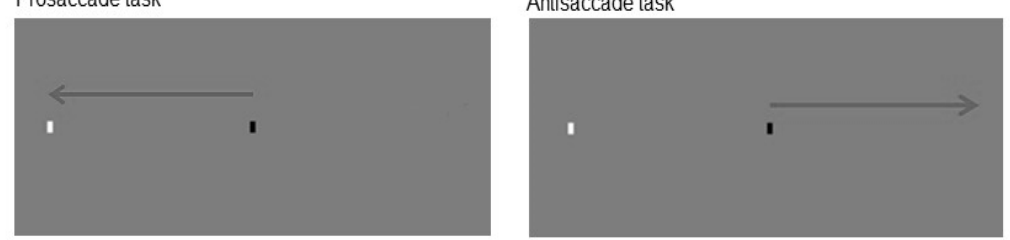

(A)

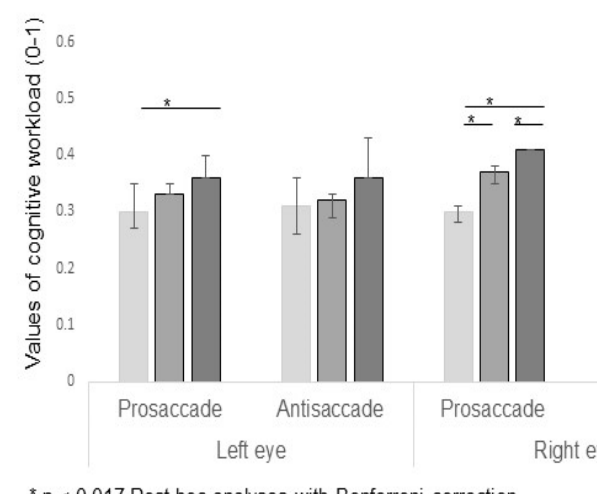

(B)

${ }^{*} p<0.017$ Post hoc analyses with Bonferroni correction

\section{Right eye}

पControls $\square$ PD-NCl $\square$ PD-Cl

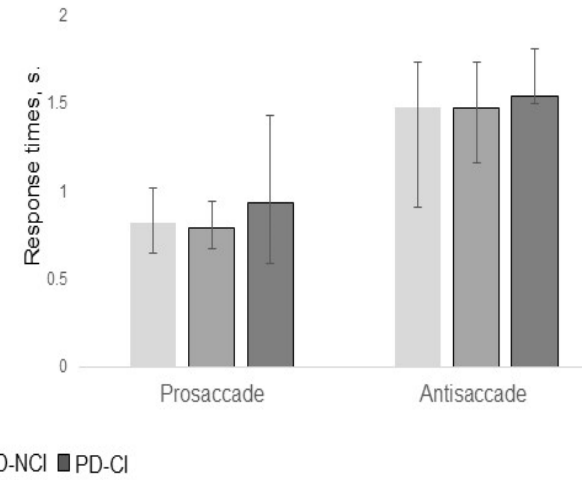

(C)

FIG.1. (A) Examples of prosaccade and antisaccade tasks (overlap condition). The arrow represents the correct eye movement. (B) Values of median cognitive workload for both eyes in the prosaccade and antisaccade tasks among controls, PD-NCI patients, and PD-CI patients. Vertical bars represent first and third quartiles $(\mathrm{Q} 1-\mathrm{Q} 3)$. Higher values reflect greater cognitive workload. When participants had more than $30 \%$ of missing data for one task, we replaced values by mean values of the group. (C) Median responses times in controls, PDNCI patients and PD-CI patients in both prosaccade and antisaccade tasks. Vertical bars represent first and third quartiles (Q1 - Q3). One control, one PD-NCI patient and four PD-CI patients did not press the button due to task difficulty. 


\section{REFERENCES}

[1] E.R. Dorsey, R. Constantinescu, J.P. Thompson, K.M. Biglan, R.G. Holloway, K. Kieburtz, F.J. Marshall, B.M. Ravina, G. Schifitto, A. Siderowf, C.M. Tanner, Projected number of people with Parkinson disease in the most populous nations, 2005 through 2030, Neurology. 68 (2007) 384-386. doi:10.1212/01.wnl.0000247740.47667.03.

[2] H. Devos, W. Vandenberghe, M. Tant, A.E. Akinwuntan, W. De Weerdt, A. Nieuwboer, E.Y. Uc, Driving and off-road impairments underlying failure on road testing in Parkinson's disease, Mov. Disord. Off. J. Mov. Disord. Soc. 28 (2013) 1949-1956. doi:10.1002/mds.25701.

[3] M. Ranchet, L. Paire-Ficout, E.Y. Uc, A. Bonnard, D. Sornette, E. Broussolle, Impact of specific executive functions on driving performance in people with Parkinson's disease, Mov. Disord. Off. J. Mov. Disord. Soc. 28 (2013) 1941-1948. doi:10.1002/mds.25660.

[4] K.F. Pedersen, J.P. Larsen, O.B. Tysnes, G. Alves, Prognosis of mild cognitive impairment in early Parkinson disease: The Norwegian ParkWest study, JAMA Neurol. 70 (2013) 580-586.

[5] C.-A. Wang, H. McInnis, D.C. Brien, G. Pari, D.P. Munoz, Disruption of pupil size modulation correlates with voluntary motor preparation deficits in Parkinson's disease, Neuropsychologia. 80 (2016) 176-184. doi:10.1016/j.neuropsychologia.2015.11.019.

[6] D. Kahneman, J. Beatty, I. Pollack, Perceptual Deficit during a Mental Task, Science. 157 (1967) 218-219. doi:10.1126/science.157.3785.218.

[7] J. Klinger, R. Kumar, P. Hanrahan, Measuring the task-evoked pupillary response with a remote eye tracker, Eye Track. Res. Appl. 69 (2008). doi:10.1145/1344471.1344489.

[8] S.P. Marshall, Identifying cognitive state from eye metrics, Aviat. Space Environ. Med. 78 (2007) B165-175.

[9] J. Beatty, Task-evoked pupillary responses, processing load, and the structure of processing resources, Psychol. Bull. 91 (1982) 276-292.

[10] J. Beatty, B. Lucero-Wagoner, The pupillary system, in: Handb. Psychophysiol., Cambridge University Press, New York, 2000.

[11] J. Orlosky, Y. Itoh, M. Ranchet, K. Kiyokawa, J. Morgan, H. Devos, Emulation of Physician Tasks in Eye-tracked Virtual Reality for Remote Diagnosis of Neurodegenerative Disease, IEEE Trans. Vis. Comput. Graph. (2017). doi:10.1109/TVCG.2017.2657018.

[12] M.R. MacAskill, C.F. Graham, T.L. Pitcher, D.J. Myall, L. Livingston, S. van Stockum, J.C. Dalrymple-Alford, T.J. Anderson, The influence of motor and cognitive impairment upon visually-guided saccades in Parkinson's disease, Neuropsychologia. 50 (2012) 3338-3347. doi:10.1016/j.neuropsychologia.2012.09.025.

[13] C.A. Antoniades, N. Demeyere, C. Kennard, G.W. Humphreys, M.T. Hu, Antisaccades and executive dysfunction in early drug-naive Parkinson's disease: The discovery study., Mov. Disord. Off. J. Mov. Disord. Soc. 30 (2015) 843-847. doi:10.1002/mds.26134.

[14] A.J. Hood, S.C. Amador, A.E. Cain, K.A. Briand, A.H. Al-Refai, M.C. Schiess, A.B. Sereno, Levodopa slows prosaccades and improves antisaccades: an eye movement study in Parkinson's disease, J. Neurol. Neurosurg. Psychiatry. 78 (2007) 565-570. doi:10.1136/jnnp.2006.099754.

[15] G. Deuschl, C. Schade-Brittinger, P. Krack, J. Volkmann, H. Schäfer, K. Bötzel, C. Daniels, A. Deutschländer, U. Dillmann, W. Eisner, D. Gruber, W. Hamel, J. Herzog, R. Hilker, S. Klebe, M. Kloss, J. Koy, M. Krause, A. Kupsch, D. Lorenz, S. Lorenzl, H.M. Mehdorn, J.R. Moringlane, W. Oertel, M.O. Pinsker, H. Reichmann, A. Reuss, G.-H. Schneider, A. Schnitzler, U. Steude, V. Sturm, L. Timmermann, V. Tronnier, T. 
Trottenberg, L. Wojtecki, E. Wolf, W. Poewe, J. Voges, German Parkinson Study Group, Neurostimulation Section, A randomized trial of deep-brain stimulation for Parkinson's disease, N. Engl. J. Med. 355 (2006) 896-908. doi:10.1056/NEJMoa060281.

[16] F. Chan, I.T. Armstrong, G. Pari, R.J. Riopelle, D.P. Munoz, Deficits in saccadic eyemovement control in Parkinson's disease, Neuropsychologia. 43 (2005) 784-796. doi:10.1016/j.neuropsychologia.2004.06.026.

[17] S. Hoops, S. Nazem, A.D. Siderowf, J.E. Duda, S.X. Xie, M.B. Stern, D. Weintraub, Validity of the MoCA and MMSE in the detection of MCI and dementia in Parkinson disease, Neurology. 73 (2009) 1738-1745. doi:10.1212/WNL.0b013e3181c34b47.

[18] K.A. Briand, W. Hening, H. Poizner, A.B. Sereno, Automatic orienting of visuospatial attention in Parkinson's disease, Neuropsychologia. 39 (2001) 1240-1249.

[19] U. Ettinger, V. Kumari, X.A. Chitnis, P.J. Corr, A.L. Sumich, S. Rabe-Hesketh, T.J. Crawford, T. Sharma, Relationship between brain structure and saccadic eye movements in healthy humans, Neurosci. Lett. 328 (2002) 225-228.

[20] D. Kimura, Y. Archibald, Motor functions of the left hemisphere, Brain J. Neurol. 97 (1974) 337-350.

[21] C.-H. Lin, R.-M. Wu, Biomarkers of cognitive decline in Parkinson's disease, Parkinsonism Relat. Disord. 21 (2015) 431-443. doi:10.1016/j.parkreldis.2015.02.010.

[22] J.M. Chambers, T.J. Prescott, Response times for visually guided saccades in persons with Parkinson's disease: a meta-analytic review, Neuropsychologia. 48 (2010) 887899. doi:10.1016/j.neuropsychologia.2009.11.006.

[23] S.C. Amador, A.J. Hood, M.C. Schiess, R. Izor, A.B. Sereno, Dissociating cognitive deficits involved in voluntary eye movement dysfunctions in Parkinson's disease patients., Neuropsychologia. 44 (2006) 1475-1482. doi:10.1016/j.neuropsychologia.2005.11.015.

[24] A.W. Michell, Z. Xu, D. Fritz, S.J.G. Lewis, T. Foltynie, C.H. Williams-Gray, T.W. Robbins, R.H.S. Carpenter, R.A. Barker, Saccadic latency distributions in Parkinson's disease and the effects of 1-dopa, Exp. Brain Res. Exp. Hirnforsch. Exp. Cerebrale. 174 (2006) 7-18. doi:10.1007/s00221-006-0412-z.

[25] H.K. Wong, J. Epps, Pupillary transient responses to within-task cognitive load variation, Comput. Methods Programs Biomed. 137 (2016) 47-63. doi:10.1016/j.cmpb.2016.08.017. 